\title{
Editorial: The Role of Ocean-Based Negative Emission Technologies for Climate Mitigation
}

\author{
David P. Keller ${ }^{1 *}$, Kerryn Brent ${ }^{2}$, Lennart T. Bach ${ }^{3}$ and Wilfried Rickels ${ }^{4}$ \\ ${ }^{1}$ GEOMAR Helmholtz Centre for Ocean Research Kiel, Kiel, Germany, ${ }^{2}$ Adelaide Law School, University of Adelaide, \\ Adelaide, SA, Australia, ${ }^{3}$ Institute for Marine and Antarctic Studies, University of Tasmania, Hobart, TAS, Australia, ${ }^{4}$ Kiel \\ Institute for the World Economy, Kiel, Germany
}

Keywords: negative emission technologies, carbon dioxide removal (CDR), ocean-based carbon dioxide removal, ocean-based NETs, climate mitigation

\section{Editorial on the Research Topic}

\section{The Role of Ocean-Based Negative Emission Technologies for Climate Mitigation}

\section{OPEN ACCESS}

Edited and reviewed by: Phil Renforth,

Heriot-Watt University, United Kingdom

${ }^{*}$ Correspondence: David P. Keller dkeller@geomar.de

Specialty section:

This article was submitted to Negative Emission Technologies,

a section of the journal Frontiers in Climate

Received: 19 July 2021

Accepted: 26 July 2021

Published: 16 August 2021

Citation:

Keller DP, Brent K, Bach LT and Rickels W (2021) Editorial: The Role of

Ocean-Based Negative Emission

Technologies for Climate Mitigation.

Front. Clim. 3:743816.

doi: 10.3389/fclim.2021.743816
Mitigating climate change is a massive challenge. Atmospheric carbon dioxide removal (CDR) with negative emission technologies (NETs) is now widely considered a necessary additional action since traditional mitigation measures, such as limiting the use of fossil fuels, have had limited success (Intergovernmental Panel on Climate Change, 2018, United Nations Environment Programme, 2020). Until now, the majority of NETs research and development has focused on land-based options such as bioenergy with carbon capture and storage (BECCS). However, ocean-based NETs can potentially also play a significant CDR role.

Like their terrestrial counterparts, ocean-based NETs seek to accelerate the uptake of atmospheric $\mathrm{CO}_{2}$ by enhancing natural sinks or by engineering the removal and storage of $\mathrm{CO}_{2}$. Currently there are too many knowledge gaps to fully assess the potential, effectiveness, efficiency, risks and co-benefits, and economic costs of most approaches. Key elements to facilitate responsible R\&D are also lacking, including governance and public acceptance (GESAMP, 2019). The purpose of this topic is to examine ocean-based NETs and the challenges associated with them from a multidisciplinary perspective.

Gattuso et al. introduce an assessment framework for ocean-based NETs in which different criteria are used to group different technologies into three policy clusters: (i) Decisive, (ii) Low Regret, and (iii) Concept Stage. They apply the assessment framework to marine BECCS, restoring and increasing coastal vegetation, enhancing open-ocean productivity, and enhancing weathering and alkalinization, comparing these ocean NETs to other (ocean-based) measures. According to their assessment, restoring and increasing coastal vegetation would be a "Low Regret" measure while the other measures are still in the "Concept Stage." Preliminary application of the framework suggests that ocean-based NETs should be scaled up by prioritizing the implementation of Decisive and Low Regret measures, and urgently improving knowledge on Concept Stage measures. 
Cox et al. discuss the importance of public perceptions, decision-making, and the role of discourse for the assessment of ocean-based NETs. They argue that ocean-based NETs will generally face greater public acceptability challenges than terrestrial NETs. In this context, they utilize public acceptability studies on Ocean Iron Fertilization, the only thoroughly investigated open ocean NET, to ask whether further research into iron fertilization is necessary because it is unlikely to ever receive social license. The question added by the Editors is: Will less well-understood methods such as Ocean Alkalinity Enhancement (OAE) follow Iron Fertilization into an "acceptability crises" once more data is available?

Bertram and Merk shed further light on this issue. They identify several key determinants of public acceptability. Oceanbased NETs which appear more "natural" are likely to have a higher degree of acceptability than "engineered" proposals. Proposals that can be contained tend to be more acceptable than those perceived as uncontrollable. Bertram and Merk note that such perceptions could result in ocean-based NETs with limited sequestration capacity being privileged over proposals with far greater capacity. They argue that we need to identify who will be affected and to what degree across the entire process-chain of ocean-based NETs to better understand how public perceptions may affect the feasibility of these proposals.

Several articles focused on OAE as a means of chemical CDR, since this approach has a high theoretical potential (Renforth and Henderson, 2017). By examining the long-term dynamics of adding a constant amount of olivine to a carbon cycle model, which includes sediment and weathering feedbacks, Köhler shows how long it would take for OAE to remove most anthropogenic $\mathrm{CO}_{2}$ in a high emission climate change scenario. This study also shows that the sequestration efficiency of ocean alkalinization has its maximum during the anthropogenic $\mathrm{CO}_{2}$ emission peak and that altered marine chemistry reverses (after 1-2 kyr) the trend from sedimentary $\mathrm{CaCO}_{3}$ dissolution to a restrengthened accumulation of $\mathrm{CaCO}_{3}$ in the sediments.

How OAE might be achieved in practice is the focus of a study by Caserini et al. that investigates the potential of using existing shipping activities and capacities to add lime, $\mathrm{Ca}(\mathrm{OH})_{2}$, to the ocean. They estimate that the maximum potential discharge of lime from all active vessels worldwide is between 1.7 and $4.0 \mathrm{Gt} /$ year. For the Mediterranean Sea potential discharge of about $186 \mathrm{Mt} /$ year is estimated.

Butenschön et al. use a high resolution $(\sim 6 \mathrm{~km})$, physical-biogeochemical model of the Mediterranean Sea to investigate the efficacy and biogeochemical side effects of adding alkalinity along current shipping routes during a moderate emission scenario (RCP 4.5). They find that with a strategic deployment scenario ocean acidification can be stopped and stabilized, while still allowing for efficient CDR.
In a more global context, Burt et al. use an Ocean carbon cycle model to show that the efficacy of OAE varies substantially across different ocean regions over a timescale of 75 years. Within the regions they tested, they found the highest efficacies of OAE when applied in a narrow circumpolar band in the Southern Ocean at $\left(\sim 55^{\circ} \mathrm{S}\right)$, while lowest efficacies were observed in the sub-polar North Atlantic. They explain the variable efficacies with regional differences in (i) physical water mass transport and (ii) the ability of the seawater carbonate system to absorb additional $\mathrm{CO}_{2}$ per amount of alkalinity added to the ocean.

This strong focus on OAE is complemented in a Frontiers for Young Minds article by Woodall et al. on enhanced mineral weathering. This article is pitched at school-aged readers, and explains the need for NETs and the potential ways in which carbon mineralization can contribute, including via the ocean. In doing so, it seeks to enhance public understanding and awareness of NETs and inspire the next generation of researchers.

In summary, the articles in this Research Topic add critical knowledge to the small, but rapidly growing body of research on ocean-based NETs. These contributions will be of particular value to guide future work as the field begins to transition from mostly theoretical perspectives to applied research and development of promising NETs. As part of this transition, inter- and trans-disciplinary research will become increasingly important to tackle the multi-dimensional challenges associated with ocean-based NETs. For some NETs this transition is yet to commence, as critical disciplinary knowledge gaps remain. However, for proposals like OAE this transition has begun in earnest, necessitating greater inter-/trans-disciplinary engagement from academia, government organizations and civil society.

\section{AUTHOR CONTRIBUTIONS}

DPK wrote the introduction and conclusion sections, as well as paragraphs for each article in the topic that he edited. KB, LTB, and WR wrote paragraphs for each article in the topic that they edited. All authors worked together to edit and improve the final text of the whole article.

\section{ACKNOWLEDGMENTS}

DPK and WR acknowledge funding from the European Union's Horizon 2020 Research and Innovation Program under grant 869357 (project OceanNETs: Ocean-based Negative Emission Technologies-analyzing the feasibility, risks, and co-benefits of ocean-based negative emission technologies for stabilizing the climate). LTB acknowledges funding from the Australian Research Council under the Future Fellowship grant FT200100846 (Enhanced Weathering-a sustainable tool for $\mathrm{CO}_{2}$ removal?). 


\section{REFERENCES}

GESAMP (2019). High Level Review of a Wide Range of Proposed Marine Geoengineering Techniques, eds P. W. Boyd and C. M. G. Vivian. IMO/FAO/UNESCO-IOC/UNIDO/WMO/IAEA/UN/UN Environment/ UNDP/ISA Joint Group of Experts on the Scientific Aspects of Marine Environmental Protection. Rep. Stud. GESAMP No. 98, $144 \mathrm{p}$.

Intergovernmental Panel on Climate Change (2018). Global Warming of $1.5^{\circ} \mathrm{C}$. An IPCC Special Report on the Impacts of Global Warming of $1.5^{\circ} \mathrm{C}$ Above Pre-Industrial Levels and Related Global Greenhouse Gas Emission Pathways, in the Context of Strengthening the Global Response to the Threat of Climate Change.

Renforth, P., and Henderson, G. (2017). Assessing ocean alkalinity for carbon sequestration. Rev. Geophys. 55, 636-674. doi: 10.1002/2016RG000533

United Nations Environment Programme (2020). Emissions Gap Report 2020. Nairobi.
Conflict of Interest: The authors declare that the research was conducted in the absence of any commercial or financial relationships that could be construed as a potential conflict of interest.

Publisher's Note: All claims expressed in this article are solely those of the authors and do not necessarily represent those of their affiliated organizations, or those of the publisher, the editors and the reviewers. Any product that may be evaluated in this article, or claim that may be made by its manufacturer, is not guaranteed or endorsed by the publisher.

Copyright (C) 2021 Keller, Brent, Bach and Rickels. This is an open-access article distributed under the terms of the Creative Commons Attribution License (CC BY). The use, distribution or reproduction in other forums is permitted, provided the original author(s) and the copyright owner(s) are credited and that the original publication in this journal is cited, in accordance with accepted academic practice. No use, distribution or reproduction is permitted which does not comply with these terms. 